\title{
SPECIFICITY OF JUMPING, ACCELERATION AND QUICK CHANGE-OF-DIRECTION MOTOR ABILITIES IN SOCCER PLAYERS
}

\author{
Asier Los Arcos ${ }^{1}$, Jurdan Mendiguchia ${ }^{2}$, and Javier Yanci ${ }^{1}$ \\ ${ }^{1}$ Faculty of Education and Sport, University of the Basque Country, \\ UPV/EHU, Vitoria-Gasteiz, Spain \\ ${ }^{2} Z$ Zentrum Rehabilitation and Performance Center, Department of Physical Therapy, \\ Barañáin, Spain
}

Original scientific paper

UDC: 796.332:796.012.1

\begin{abstract}
:
The purpose of this study was to determine the underlying structure of the stretch-shortening cycle (SSC) jumping, acceleration and change-of-direction (COD) abilities in soccer players using principal component factor analysis (PCA). Based on the results of recent studies on male college athletes, we hypothesized that slow SSC jumping, acceleration and COD represent independent motor abilities in soccer players. Forty two soccer players $(23.2 \pm 2.36 \mathrm{yr})$ performed three tests for each group of rapid lower-body movements: a) three vertical slow SSC jumping tests - squat jump (SJ), countermovement jump (CMJ) and arm swing countermovement jump (CMJAS), b) three acceleration tests $-5,10$ and 15 meter sprint times (ACC5, ACC10 and ACC15), and c) three COD tests - modified agility test free (MATF), the 505 agility test (505) and 20 yard agility test (Y20). PCA was applied to establish the relationships among the factors (i.e. motor abilities) underlying the included manifest variables (i.e. performance tests). This procedure reduced all variables to a smaller number of independent latent dimensions. The results indicated three separate factors that may correspond to slow SSC jumping, acceleration and COD abilities. The magnitude of the correlation coefficients among the three motor abilities extracted was $\mathrm{r}<.56$. Therefore, it is suggested that slow SSC jumping, acceleration and COD abilities represent independent motor abilities and consequently these should be trained and evaluated separately to assess soccer players' physical profiles.
\end{abstract}

Key words: football, performance, vertical jump, sprint, agility

\section{Introduction}

Soccer players are required in an endurance context to turn, sprint and change pace during matches (Stølen, Chamari, Castagna, \& Wisløff, 2005). Specifically, during competitive matches, soccer players perform about 1300 changes of activities (Bloomfield, Polman, \& O'Donoghue, 2007; Sarmento, et al., 2014; Stølen, et al., 2005), including 220 high-intensity actions (Di Salvo, et al., 2007) and 2-4 s accelerations approximately every $90 \mathrm{~s}$ (Stølen, et al., 2005; Vigne, Gaudino, Rogowski, Alloatti, \& Hautier, 2010) at near maximal intensity. Due to importance of these different rapid movements during a soccer game (Hoff, 2005), jumping, acceleration and changes-of-direction (COD) abilities have been widely tested to evaluate neuromuscular performance. With this aim, numerous types of jumps (Caldwell \& Peters, 2009; Casajus \& Castagna, 2007; Kalapotharakos, et al., 2006; Lockie, et al., 2014; Stølen, et al., 2005; Wisløff, Castagna, Helgerud, Jones, \& Hoff, 2004; Yanci, Los Arcos, Mendiguchia, \& Brughelli, 2014), different sprinting distances (Caldwell \& Peters, 2009; Gissis, et al., 2006; Lockie, et al., 2014; Magal, Smith, Dyer, \& Hofman, 2009; Reilly, Williams, Nevill, \& Franks, 2000; Rosch, et al., 2000; Stølen, et al., 2005; Taskin, 2008; Vescovi \& McGuigan, 2008; Wisløff, et al., 2004; Yanci, et al., 2014) and different types of CODs (number of CODs, force applications and distances) (Caldwell \& Peters, 2009; Lockie, et al., 2014; Magal, et al., 2009; Reilly, et al., 2000; Stølen, et al., 2005; Vescovi \& McGuigan, 2008; Yanci et al., 2014) have been applied. However, to date, there is no consensus about which is the best way (i.e. test battery) to test these abilities (Rosch, et al., 2000).

Despite numerous studies that have examined the relationship between jumping, sprinting and 
agility/change-of-direction performance in different soccer codes and players (Buttifant, Graham, \& Cross, 2009; Gorostiaga, et al., 2009; Little \& Williams, 2005; Lockie, et al., 2014; McCurdy, et al., 2010; Sheppard, Young, Doyle, Sheppard, \& Newton, 2006; Vescovi \& McGuigan, 2008; Wisløff, et al., 2004; Yanci, et al., 2014), the association among these abilities remains unclear. Several studies have found weak associations in professional (Little \& Williams, 2005), junior (Buttifant, et al., 2009) and amateur (Yanci, et al., 2014) soccer players. In addition, the association magnitude between jumping and sprinting tests varied considerably with regard to sprint distance and jump type (i.e. unilateral vs. bilateral and horizontal vs. vertical) in elite soccer players (Gorostiaga, et al., 2009; Wisløff, et al., 2004). Finally, in relation to COD-jumping associations, the correlation magnitudes ranged from .09 to .69 in amateur soccer players (Yanci, et al., 2014), and considerable differences in the correlation coefficients were found in other papers (Brughelli, Cronin, Levin, \& Chaouachi, 2008; Chaouachi, et al., 2012), showing evidence of the controversy among the studies that have assessed the association among these three abilities.

Together with other factors (i.e. soccer code, competitive level), the use of different jumping, sprinting and agility/COD tests further complicates the comparison of the studies. However, this problem can be avoided through factorial analysis using principal component factor analysis (PCA) (Nunnally \& Bernstein, 1994), and the limitations of the correlation use (Vescovi \& McGuigan, 2008) can be overcome. Multivariate statistical techniques have been proposed to advance our knowledge regarding the mentioned structure of motor abilities (Salaj \& Markovic, 2011). These authors proposed PCA and calculated the relationships among several factors (change-of-direction speed, slow and fast stretch-shortening cycle [SSC], jumping ability and sprinting ability) in male college athletes. Similarly, other studies have linked agility and strength qualities (Marković, Sekulić, \& Marković, 2007) or agility and leg extensor strength and power (Marković, 2007) in male physical education students. However, to date, we have not found any studies that have conducted this type of analysis among jumping, acceleration and COD abilities of soccer players using different types of tests.

Therefore, the main aim of the study was to analyse the specificity of jumping, acceleration and quick change-of-direction abilities in soccer players. We also proposed the use of PCA to determine the underlying structure of slow SCC jumping, acceleration and COD abilities. Based on the results of recent studies on male college athletes (Salaj \& Markovic, 2011), we hypothesized that slow SSC jumping, acceleration and COD represent independent motor abilities in soccer players.

\section{Methods}

\section{Participants}

Forty two male soccer players (age: $23.2 \pm 2.4$ years; body mass: $76.6 \pm 8.2 \mathrm{~kg}$; body height: $179.6 \pm 5.8 \mathrm{~cm}$; body fat: $13.2 \pm 4.2 \%$ ) participated in this study. They competed in the Spanish $2^{\text {nd }}$ $\mathrm{B}$ and $3^{\text {rd }}$ division championships and trained 3-5 times per week during the study: a) $2^{\text {nd }} \mathrm{B}$ division team: Monday - recovery or compensatory session; Wednesday - strength training and smallsided games, Thursday - technical drills and largesided games; Friday - technical and tactical drills, Saturday - tactical training; b) $3^{\text {rd }}$ division team: Tuesday - continuous running or interval training and technical-tactical exercises, Wednesday small-sided games; Friday - speed drills and tactical training. The players had at least 13 years of soccer training experience. The study was conducted according to the Declaration of Helsinki and was approved by the local ethics committee.

\section{Procedure}

We examined the relationship among slow SSC jumping, acceleration and COD abilities in soccer players using PCA to establish the relationships among the factors (i.e. motor abilities) underlying the included manifest variables (i.e. performance tests). The applied tests were: a) vertical SSC jumping tests (squat jump [SJ], countermovement jump [CMJ], and arm swing countermovement jump [CMJAS]), b) acceleration tests (5-, 10 - and 15-meter sprint times [ACC5, ACC10 and $\mathrm{ACC} 15]$ ), and c) COD tests (modified agility test free [MATF], the 505 agility test [505], and 20-yard agility test [Y20]).

In order to assess neuromuscular performance, the players completed the same physical testing battery at the end of the season (i.e. in June). Players were familiarized with the testing procedures during the in-season testing and training sessions. The test procedure consisted of one session with the following test order: jump tests (i.e. SJ, CMJ, CMJAS), COD tests (i.e. MATF, Y20, 505) and sprint tests. All players performed the tests at the same time of the day (7-9 p.m.) and on an indoor surface. During the testing session, the subjects wore T-shirts, shorts and standard athletic shoes. Subjects completed a standardized warm-up consisting of 3 minutes jogging followed by a skipping and scalping exercise, stride length and three accelerations with change of direction. Before each test, the subjects had the opportunity to perform a non-registered trial. The study was supervised by the researchers, and the best result of the three trials of each test was used for further analysis. The subjects were requested not to perform strenuous exercise 48 hours before the testing session. 


\section{Jumping.}

The players performed three jumps of each type of vertical jump test (i.e. SJ, CMJ, CMJAS). In all tests, the recovery time between jumps was 20 seconds and emphasis was placed on performing the exercise correctly. Any jump that did not meet the considered requirements was excluded from calculations and repeated. All jumps were assessed using an optical measurement system (Optojumpnext, Microgate, Bolzano, Italy).

SJ: Subjects squatted down until the knees were bent at 90 degrees, keeping the trunk straight, and jumped from this semi squatting position without any countermovement. The participants kept their hands on the hips throughout the test. The athlete jumped vertically as high as possible. Both the takeoff and landing had to be from and on both feet, with no initial steps or shuffling (Komi \& Bosco, 1978). The intraclass correlation coefficient (ICC) was .952.

$C M J$ : For $C M J$, as proposed by Bosco and Komi (1979), the vertical-jump standardization was achieved by requiring a $90^{\circ}$ knee bend, keeping hands on the waist throughout the jump, avoiding undue lateral and frontal movements and landing on straight legs after each jump. The ICC was .976.

CMJAS: Like the CMJ jump protocol, but allowing an arm swing. The ICC was .973.

\section{Change-of-direction ability (CODA).}

The players performed of each type of COD test three times (i.e. MATF, Y20 and 505). In all the tests recovery time between repetitions lasted at least 3 minutes and emphasis was placed on performing the exercise correctly. Any trial that did not meet the considered requirements was excluded from calculations and repeated. All COD tests were assessed using the same timing gates (Powertimer, Newtest ${ }^{\circledR}$ Oy, Oulu, Finland).

MATF (Figure 1A): The soccer players began with both feet together $0.5 \mathrm{~m}$ away from cone A, and completed the protocol according to Sassi et al. (2009). The players performed the test using the same directives, but were not required to move laterally or face forward. The players had to touch the top of the cone instead of its base. A-B distance $(5 \mathrm{~m})$ : At his own discretion, each subject sprinted forward to cone $\mathrm{B}$ and touched the top of the cone with the right hand. B-C distance $(2.5 \mathrm{~m})$ : Facing forward the participant shuffled to the left to cone $\mathrm{C}$ and touched the top of the cone with the left hand. $\mathrm{C}$-D distance $(5 \mathrm{~m})$ : The soccer player then shuffled to the right to cone D and touched its top. D-B distance $(2.5 \mathrm{~m})$ : The participant shuffled back to the left to cone B and touched its top. B-A distance $(5 \mathrm{~m})$ : Finally, the soccer player moved as quickly as possible and returned to line $\mathrm{A}$. The total distance covered was $20 \mathrm{~m}$, and the height of the cones was $0.3 \mathrm{~m}$. Time measurement started and finished when the subject crossed the line between the tripods. The ICC was .799.

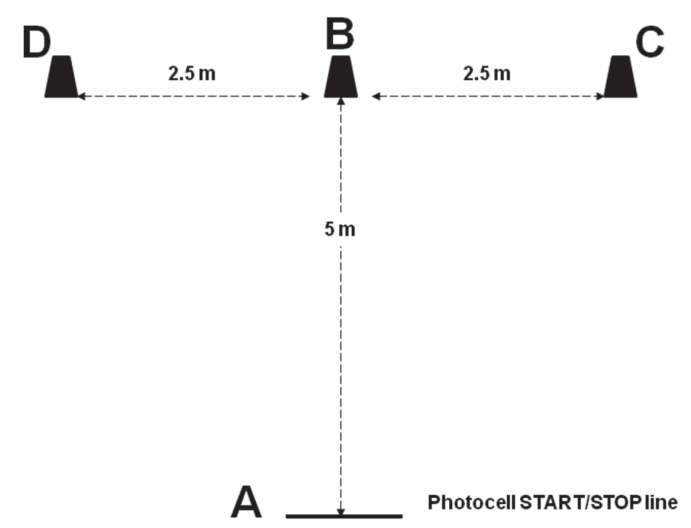

Figure 1A). Modified agility test free (MATF).

Y20 (Figure 1B): A 2-ft piece of tape was placed on an indoor surface to mark the center line. Five yards (i.e. $4.57 \mathrm{~m}$ ) were measured from the center line in both directions and these spots were also marked with the tape. Each subject was instructed to straddle the center line with his feet on the line. On the given command, the subject ran towards the line of his choice and touched it with his foot, changed direction and ran past the center line to the opposite line and touched it with his foot. The subject again changed direction by pivoting and ran through the center line. The drill was over when the subject's body crossed the center line. The ICC was .715.

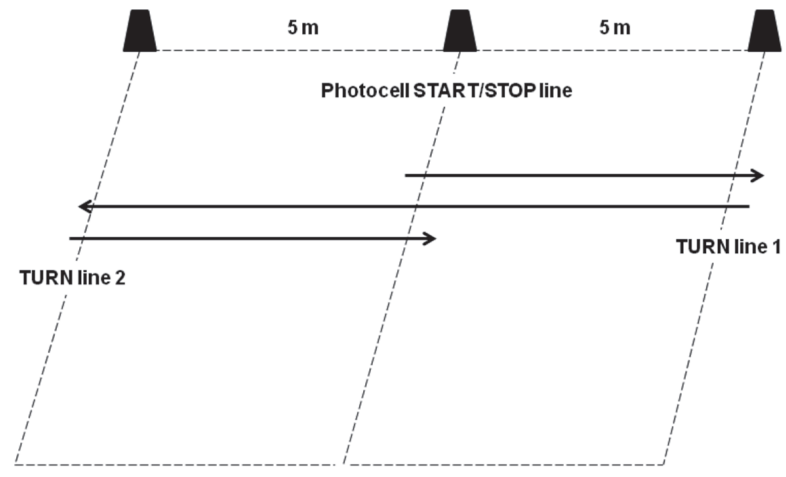

Figure 1B). Twenty-yard agility test (Y20).

505 (Figure 1C): The athlete sprinted forward to a line $5 \mathrm{~m}$ ahead and pivoted $180^{\circ}$ before returning to the start position (Sheppard \& Young, 2006). Time measurement started and finished when the subject crossed the line between the tripods. The ICC was .874. 


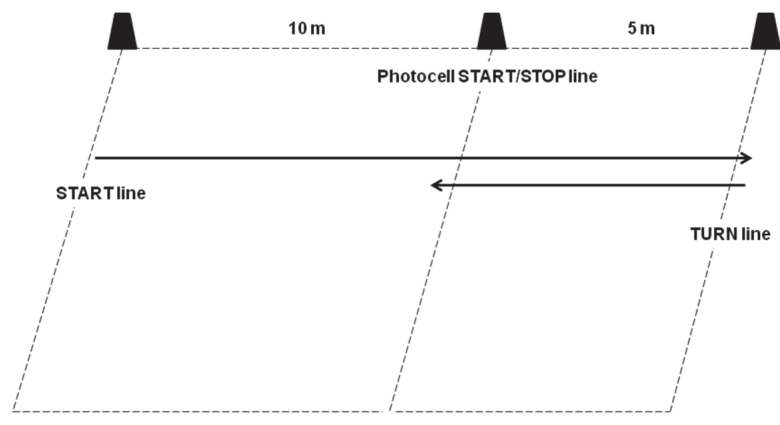

Figure 1C). 505 agility test (505).

\section{Acceleration.}

The sprint test consisted of three maximum accelerations of $15 \mathrm{~m}$ with a 3 -minute rest between each one (Los Arcos, et al., 2014). Subjects were placed at $0.5 \mathrm{~m}$ in front of the timing gate (Microgate ${ }^{\circledR}$ Polifemo, Bolzano, Italy) placed $0.4 \mathrm{~m}$ above the ground and with an accuracy of $1 \mathrm{~ms}$. Split times were recorded at $5 \mathrm{~m}, 10 \mathrm{~m}$ and $15 \mathrm{~m}$ (ACC5, $A C C 10$, and $A C C 15$ ). ICC values were $.873, .927$ and .957 for $5 \mathrm{~m}, 10 \mathrm{~m}$ and $15 \mathrm{~m}$ times, respectively.

\section{Statistical analysis}

Results are presented as mean \pm standard deviations. The relationship among jumping, acceleration and COD tests was calculated using Pearson's product-moment method $(90 \%$ confidence limits). The magnitude of correlation among test measures was assessed with the following thresholds: $<.1$, trivial; $=.1-.3$, small; .3-.5, moderate; $.5-.7$, large; .7-.9, very large, and .9-1.0, almost perfect (Hopkins, Marshall, Batterham, \& Hanin, 2009). Practical inferences of the correlation coefficients were considered (Hopkins, 2007). The corresponding intercorrelation matrix of all selected variables was factorized using PCA (Nunnally \& Bernstein, 1994). The data were analysed using a procedure called FACTOR in the SPSS (version 23.0) software package. The number of significant principal components in the factor pattern matrix extracted by PCA was determined by the Kaiser-Guttman criterion (Nunnally \& Bernstein, 1994), which retains principal components with eigenvalues $>1$. The original factor pattern matrix was rotated to improve the simple structure of the matrix. This rotation was nonorthogonal and used a promax criterion with Kaiser normalization. The final PCA outcomes were commonalities and factor loadings for each manifest variable, eigenvalues and percentages of variance were explained by each rotated principal component. Intercorrela- tions among the extracted principal components were also calculated. To support our hypotheses, the PCA was expected to reveal three independent principal components, and their factor structure should have allowed the identification of the following motor abilities: (a) slow SSC jumping ability, (b) acceleration ability and (c) COD ability. Statistical significance was set at $\mathrm{p}<.05$.

\section{Results}

Table 1 shows the results in all acceleration, COD and jump tests.

Table 1. Mean $( \pm S D)$ results and range of all selected acceleration, change-of-direction speed and jump tests $(n=42)$

\begin{tabular}{lcc}
\hline & M \pm SD & Range \\
\hline SJ $(\mathrm{cm})$ & $35.30 \pm 4.76$ & $25.30-44.70$ \\
CMJ $(\mathrm{cm})$ & $40.94 \pm 4.93$ & $33.00-51.80$ \\
CMJAS $(\mathrm{cm})$ & $49.10 \pm 5.92$ & $37.80-62.50$ \\
MATF $(\mathrm{s})$ & $4.91 \pm .16$ & $4.57-5.29$ \\
Y20 $(\mathrm{s})$ & $4.84 \pm .17$ & $4.52-5.26$ \\
505 $(\mathrm{s})$ & $2.51 \pm .09$ & $2.32-2.77$ \\
ACC15 $(\mathrm{s})$ & $2.35 \pm .09$ & $2.15-2.53$ \\
ACC5 $(\mathrm{s})$ & $.99 \pm .05$ & $.88-1.08$ \\
ACC10 $(\mathrm{s})$ & $1.70 \pm .07$ & $1.55-1.87$ \\
ACC15 $(\mathrm{s})$ & $2.35 \pm .09$ & $2.15-2.53$ \\
\hline
\end{tabular}

Note. $\mathrm{SJ}=$ squat jump test; $\mathrm{CMJ}=$ Countermovement jump test; CMJAS=Arm swing countermovement jump test; MATF=Modified agility test free; $Y 20=20$-yd agility test; $505=505$ agility test; $A C C 15=15 \mathrm{~m}$ sprint; $A C C 5=5 \mathrm{~m}$ sprint; ACC $10=10 \mathrm{~m}$ sprint.

The correlation magnitudes among acceleration, COD and jumping tests varied considerably depending on the test used (from small to large) (Table 2).

The PCA reduced nine manifest variables to three principal components (i.e. factors), which explained $84.68 \%$ of the variance of all variables (Table 3). Acceleration tests had the highest factor loadings (correlations) with the first principal component; the second principal component was highly correlated with the three COD tests, and the third principal component was highly correlated with the three jumping tests.

Finally, the correlation coefficient (r) among the three extracted principal components was in all cases lower than .55 , pointing to the relative independence (i.e. specificity) of each principal component (Table 4). 
Table 2. Intercorrelations ( $\pm 90 \%$ confidence limits) among all selected jump, sprinting and change-of-direction speed tests

\begin{tabular}{|c|c|c|c|c|c|c|c|c|}
\hline & ACC5 & ACC10 & ACC15 & MATF & 505 & Y20 & SJ & CMJAS \\
\hline ACC10 & $\begin{array}{c}.90 ; \pm .05^{* *} \\
\text { Most likely almost perfect } \\
100 / 0 / 0\end{array}$ & - & & & & & & \\
\hline ACC15 & $\begin{array}{c}.87 ; \pm .07^{* *} \\
\text { Most likely very large } \\
100 / 0 \%\end{array}$ & $\begin{array}{c}.95 ; \pm .03 * \\
\text { Most likely almost perfect } \\
\text { 100//0 }\end{array}$ & - & & & & & \\
\hline MATF & $\begin{array}{c}.50 ; \pm .20 * \\
\text { Most likely large } \\
100 / / 0\end{array}$ & $\begin{array}{c}.51 ; \pm .19 * \\
\text { Most likely large } \\
\text { 100//0 }\end{array}$ & $\begin{array}{c}.53 ; \pm .19 * \\
\text { Most likely large } \\
100 / 0 / 0\end{array}$ & - & & & & \\
\hline 505 & $\begin{array}{c}.28 ; \pm .24 \\
\text { Likely small } \\
88 / 111 / 1\end{array}$ & $\begin{array}{c}.41 ; \pm .22 * \\
\text { Very likely moderate } \\
98 / 2 / 0\end{array}$ & $\begin{array}{c}.41 ; \pm .22 * \\
\text { Very likely moderate } \\
98 / 2 / 0\end{array}$ & $\begin{array}{c}.49 ; \pm .20 * \\
\text { Most likely moderate } \\
100 / 0 / 0\end{array}$ & - & & & \\
\hline Y20 & $\begin{array}{l}.26 ; \pm .24 \\
\text { Likely small } \\
85 / 14 / 1\end{array}$ & $\begin{array}{c}.40 ; \pm .22 \\
\text { Very likely moderate } \\
98 / 2 / 0\end{array}$ & $\begin{array}{c}.42 ; \pm .21^{* *} \\
\text { Very likely moderate } \\
99 / 1 / 0\end{array}$ & $\begin{array}{c}.65 ; \pm .15 \\
\text { Most likely large } \\
100 / 0 / 0\end{array}$ & $\begin{array}{c}.65 ; \pm .15 * \\
\text { Most likely large } \\
100 / 0 / 0\end{array}$ & - & & \\
\hline SJ & $\begin{array}{c}.33 ; \pm .23^{*} \\
\text { Likely moderate } \\
94 / 6 / 0\end{array}$ & $\begin{array}{c}.33 ; \pm .23^{*} \\
\text { Likely moderate } \\
94 / 6 / 0\end{array}$ & $\begin{array}{c}.38 ; \pm .22 * \\
\text { Very likely moderate } \\
97 / 3 / 0\end{array}$ & $\begin{array}{c}.32 ; \pm .23^{*} \\
\text { Likely moderate } \\
93 / 710\end{array}$ & $\begin{array}{c}.49 ; \pm .20 " \\
\text { Most likely moderate } \\
100 / \% 10\end{array}$ & $\begin{array}{c}.34 ; \pm .23^{*} \\
\text { Likely moderate } \\
94 / 6 / 0\end{array}$ & - & \\
\hline CMJAS & $\begin{array}{c}.46 ; \pm .21^{* *} \\
\text { Very likely moderate } \\
99 / 1 / 0\end{array}$ & $\begin{array}{c}.51 ; \pm .19+ \\
\text { Most likely large } \\
\text { 100//0/0 }\end{array}$ & $\begin{array}{c}.62 ; \pm .16 * \\
\text { Most likely large } \\
\text { 100//0 }\end{array}$ & $\begin{array}{c}.55 ; \pm .18^{* *} \\
\text { Most likely large } \\
100 / 0 / 0\end{array}$ & $\begin{array}{c}.49 ; \pm .2 * \\
\text { Most likely moderate } \\
100 / 0 / 0\end{array}$ & $\begin{array}{c}.44 ; \pm .21^{* *} \\
\text { Very likely moderate } \\
99 / 1 / 0\end{array}$ & $\begin{array}{c}.68 ; \pm .14 * \\
\text { Most likely large } \\
100 / / 0\end{array}$ & - \\
\hline CMJ & $\begin{array}{c}.49 ; \pm .20^{* *} \\
\text { Most likely moderate } \\
100 / \% 0\end{array}$ & $\begin{array}{c}.53 ; \pm .19^{\text {** }} \\
\text { Most likely large } \\
100 / / 0\end{array}$ & $\begin{array}{l}.64 ; \pm .16^{* *} \\
\text { Most likely large } \\
\text { 100/\%/0 }\end{array}$ & $\begin{array}{c}.49 ; \pm .20 * \\
\text { Most likely moderate } \\
100 / / 0\end{array}$ & $\begin{array}{c}.44 ; \pm .21^{* *} \\
\text { Very likely moderate } \\
\text { 99/1/10 }\end{array}$ & $\begin{array}{c}.47 ; \pm .20 * \\
\text { Very likely moderate } \\
99 / 1 / 0\end{array}$ & $\begin{array}{c}.80 ; \pm .10 * \\
\text { Most likely very large } \\
100 / \% 0\end{array}$ & $\begin{array}{c}.87 ; \pm .07^{* *} \\
\text { Most likely very large } \\
\text { 100//0/0 }\end{array}$ \\
\hline
\end{tabular}

Note. ACC5=5 m sprint; ACC10=10 m sprint; ACC15=15 m sprint; MATF=Modified agility test free; 505=505 agility test; Y20=20-yd agility test; SJ=squat jump test; CMJAS=Arm swing countermovement jump test; $\mathrm{CMJ}=$ Countermovement jump test.

Chances that the true value of the effect statistic is...: substantially +ive / trivial / substantially -ive (e.g. 100/0/0).

Table 3. Results of principal component factor analysis*

\begin{tabular}{lcccc}
\hline & \multicolumn{4}{c}{ Factor loadings } \\
\cline { 2 - 5 } ACC5 & 1 & 2 & 3 & Commonalities \\
\cline { 2 - 5 } ACC10 & .953 & .436 & .372 & .920 \\
ACC15 & .973 & .472 & .498 & .949 \\
MATF & .967 & .568 & .519 & .944 \\
505 & .577 & .449 & .813 & .708 \\
Y20 & .349 & .544 & .829 & .711 \\
SJ & .375 & .424 & .917 & .851 \\
CMJAS & .341 & .913 & .427 & .856 \\
CMJ & .570 & .899 & .569 & .829 \\
Eigen value & .583 & .952 & .543 & .920 \\
\% of variance & 5.25 & 1.39 & 1.05 & \\
\hline
\end{tabular}

Note. Factor 1=Acceleration; Factor 2=Jumping; Factor $3=$ Change of Direction; $A C C 5=5 \mathrm{~m}$ sprint; $A C C 10=10 \mathrm{~m}$ sprint; $A C C 15=15 \mathrm{~m}$ sprint; MATF=Modified free agility test; 505 $=505$ agility test; $Y 20=20$-yd agility test; $\mathrm{SJ}=$ squat jump test; CMJAS=Arm swing countermovement jump test; $\mathrm{CMJ}=$ Countermovement jump test.

* The highest correlations with principal components are bolded.

\section{Discussion and conclusions}

The main aim of the study was to analyse the specificity of jumping, acceleration and quick change-of-direction abilities in soccer players. We hypothesized that slow SSC jumping, acceleration and COD represent independent motor abilities in soccer players. In order to address the limita-
Table 4. Correlations $(90 \%$ confidence interval) among the extracted principal components

\begin{tabular}{lcc}
\hline $\begin{array}{l}\text { Principal } \\
\text { components }\end{array}$ & Acceleration & Jumping \\
\hline & $-.51 ; \pm .19^{* *}$ & \\
Jumping & Most likely large & - \\
& $100 / 0 / 0$ & \\
Change of & $.49 ; \pm .20^{* *}$ & $-.54 ; \pm .19^{* *}$ \\
direction & Most likely large & Most likely large \\
& $100 / 0 / 0$ & $100 / 0 / 0$ \\
\hline
\end{tabular}

Note. ${ }^{*}$ Correlation is significant at the .01 level.

tion of correlation analysis, a multivariate statistical technique was used to understand the relationship among the slow SSC jumping, acceleration and COD abilities. Taking into account that the simple and interpretable factor structure of the nine performance tests used was obtained and that the association between the extracted three motor abilities was, at most, .55, we suggest that slow SSC jumping, acceleration and COD abilities represent independent motor abilities in adult soccer players.

As we have explained, the results obtained on the association between acceleration, COD and jumping ability tests using correlation analysis have been contradictory. We also found considerable disparity in the correlation magnitudes (from small to large) in this study. The association magnitudes between COD and acceleration tests ranged from small to large $(r=.26-.53)$ (Table 2$)$ as other 
studies have shown in several team sports (Buttifant, et al., 2009; Little \& Williams, 2005; Sheppard, et al., 2006; Vescovi \& McGuigan, 2008; Yanci, et al., 2014). Similarly and in concordance with other studies (Gorostiaga, et al., 2009; McCurdy, et al., 2010; Wisløff, et al., 2004; Yanci, et al., 2014), the association magnitudes between jumping and sprinting tests varied considerably depending on sprint distance and jump type (from -.33 to -.64). The greater correlation according to the bilateral jumps used was between ACC15 and $\mathrm{CMJ}(\mathrm{r}=-.64)$, similar to the results of other studies performed with elite (Gorostiaga, et al., 2009; Wisløff, et al., 2004) and amateur (Yanci, et al., 2014) soccer players. In addition, the association between slow SSC jumping and COD tests never exceeded a correlation coefficient of $\mathrm{r}=-.55$. Among other factors, the characteristics of the tests (i.e. time to complete the test, No. of CODs, and primary application of force throughout the entire test) (Brughelli, et al., 2008; Chaouachi, et al., 2012) could explain contradictory results found in this and other studies (Yanci, et al., 2014). For example, tests of different durations may be subject to the influence of energetics rather than just assessing COD ability. Namely, each COD requires a braking force followed by a propulsive force, which in turn may increase the importance of eccentric-concentric muscle force capability and endurance as the number of turns increases (Brughelli, et al., 2008). Therefore, the association among COD, jump and acceleration tests in soccer players remains unclear.

The associations between the first principal factor and the three acceleration tests were the highest $(\mathrm{r}=.95-.97)$, while the correlation among the rest of the tests ranged from .34 to .58 . These results suggest that the first obtained principal component could represent acceleration ability in soccer players. In the same way, the second principal component correlated highly with the jumping tests $(\mathrm{r}=.90-.95)$, but this did not occur with the test addressing other motor abilities. Therefore, the second principal component could represent slow SSC jumping ability in soccer players. The last principal component correlated with the three COD tests $(\mathrm{r}=.81-.92)$ better than with the other tests $(\mathrm{r}=.37-.57)$. The third component could represent COD ability in soccer players. Our results agree with those of Salaj and Markovic (2011) despite these authors used two different COD tests (i.e. lateral stepping, LS, and figure-of-eight run, FIG8), different sprint distances (i.e. maximal sprint from a crouch start over distances of $20 \mathrm{~m}$, SPR 20 , and maximal sprint from a 'flying' start over a $20 \mathrm{~m}$ distance, FLY20) for acceleration and a standing long jump (i.e. SLJ) in testing male college athletes. Therefore, the same motor abilities can be determined through different but similar types of tests and with different populations.
We found that performance in some COD, jumping or acceleration tests correlated better with the scores obtained in other tests of the same component with their corresponding components (i.e. motor abilities) (Table 3). In line with Salaj and Markovic (2011), the correlation between performance in different jump tests and jumping ability was higher with the CMJ test $(\mathrm{r}=.952)$ than with the rest of jump tests. In addition, performance in CMJ correlated very highly with the jumping component in U-15 ( $\mathrm{r}=.96), \mathrm{U}-18(\mathrm{r}=.93)$ and adult $(\mathrm{r}=.97)$ soccer players (Rodriguez-Rosell, MoraCustodio, Franco-Márquez, Yáñez-García, \& González-Badillo, 2017), which suggests the use of this generic jump test to assess jump ability. Also, in agreement with the study carried out with male college athletes (Salaj \& Markovic, 2011), performance in the Y20 test presented a higher correlation $(\mathrm{r}=.917)$ with the COD component than others test (i.e. MATF and 505; $\mathrm{r}<.829$ ). Even though the rest of the COD tests can be used, the Y20 seems to be an interesting option to assess COD in adult males. The magnitude of the associations between performances in all sprint tests (i.e. 5, 10 and $15 \mathrm{~m}$ ) and the acceleration component was very similar $(\mathrm{r}=.953$ -.973 ), and higher than the magnitudes described by Salaj and Markovic (2011) for $5(\mathrm{r}=.87)$ and 10 $\mathrm{m}(\mathrm{r}=.92)$ sprints tests, but very similar in comparison to the association found with performance in the $20 \mathrm{~m}$ sprint test $(\mathrm{r}=.96)$, suggesting the use of distances of 10-20 meters to assess the acceleration component in male adults.

The associations among the extracted three motor abilities (i.e. acceleration, slow SSC jumping and COD abilities) were from moderate to large, but the correlation coefficient never exceeded the value of .54 (Table 4): from .49 to .54. These values were similar to the results observed in another study with male college athletes (Salaj \& Markovic, $2011)$ with respect to acceleration-COD $(r=.37)$ and acceleration-jumping $(\mathrm{r}=-.48)$ associations, but not regarding the jumping-COD relationship $(\mathrm{r}=-.25)$. The characteristics of the participants, as well as acceleration, jumping and change-of-direction demands of sporting activities in question (soccer vs. several team, racquet or combat sports) could explain the differences in the magnitude of the correlations between the studies. Even so, collectively, the results suggest that slow SSC jumping, acceleration and COD abilities are independent also in male adult soccer players.

Therefore, slow SSC jumping, acceleration and COD abilities should be evaluated separately in order to determine neuromuscular performance of soccer players. In addition, this suggests that each motor ability needs to be trained specifically, that is, the design of strength and conditioning programs should consider the independence of these three abilities. 


\section{References}

Bloomfield, J., Polman, R., \& O’Donoghue, P. (2007). Physical demands of different positions in FA Premier League Soccer. Journal of Sports Science and Medicine, 6(1), 63-70.

Bosco, C., \& Komi, P.V. (1979). Mechanical characteristics and fiber composition of human leg extensor muscles. European Journal of Applied Physiology and Occupational Physiology, 41(4), 275-284.

Brughelli, M., Cronin, J., Levin, G., \& Chaouachi, A. (2008). Understanding change of direction ability in sport: A review of resistance training studies. Sports Medicine, 38(12), 1045-1063.

Buttifant, D., Graham, K., \& Cross, K. (2009). Agility and speed of soccer players are two different performance parameters. In W. Spinks, T. Reilly \& A. Murphy (Eds.), Science and Football IV (pp. 329-332). London: Routledge.

Caldwell, B.P., \& Peters, D.M. (2009). Seasonal variation in physiological fitness of a semiprofessional soccer team. Journal of Strength and Conditioning Research, 23(5), 1370-1377.

Casajus, J.A., \& Castagna, C. (2007). Aerobic fitness and field test performance in elite Spanish soccer referees of different ages. Journal of Science and Medicine in Sport, 10(6), 382-389.

Chaouachi, A., Manzi, V., Chaalali, A., Wong, D.P., Chamari, K., \& Castagna, C. (2012). Determinants analysis of change-of-direction ability in elite soccer players. Journal of Strength and Conditioning Research, 26(10), 2667-2676.

Di Salvo, V., Baron, R., Tschan, H., Calderon Montero, F.J., Bachl, N., \& Pigozzi, F. (2007). Performance characteristics according to playing position in elite soccer. International Journal of Sports Medicine, 28(3), 222-227.

Gissis, I., Papadopoulos, C., Kalapotharakos, V.I., Sotiropoulos, A., Komsis, G., \& Manolopoulos, E. (2006). Strength and speed characteristics of elite, subelite and recreational young soccer players. Research in Sports Medicine, 14(3), 205-214.

Gorostiaga, E.M., Llodio, I., Ibáñez, J., Granados, C., Navarro, I., Ruesta, M., Bonnabau, H., \& Izquierdo, M. (2009). Differences in physical fitness among indoor and outdoor elite male soccer players. European Journal of Applied Physiology, 106(4), 483-491.

Hoff, J. (2005). Training and testing physical capacities for elite soccer players. Journal of Sports Science, 23(6), $573-582$.

Hopkins, W. (2007). A spreadsheet for deriving a confidence interval, mechanistic inference and clinical inference from a p value. Sportscience, 11, 16-20. (sportsci.org/2007/wghinf.htm).

Hopkins, W.G., Marshall, S.W., Batterham, A.M., \& Hanin, J. (2009). Progressive statistics for studies in sports medicine and exercise science. Medicine and Science in Sports and Exercise, 41(1), 3-13.

Kalapotharakos, V.I., Strimpakos, N., Vithoulka, I., Karvounidis, C., Diamantopoulos, K., \& Kapreli, E. (2006). Physiological characteristics of elite professional soccer teams of different ranking. Journal of Sports Medicine and Physical Fitness, 46(4), 515-519.

Komi, P.V., \& Bosco, C. (1978). Utilization of stored elastic energy in leg extensor muscles by men and women. Medicine and Science in Sports, 10(4), 261-265.

Little, T., \& Williams, A.G. (2005). Specificity of acceleration, maximum speed, and agility in professional soccer players. Journal of Strength and Conditioning Research, 19(1), 76-78.

Lockie, R.G., Callaghan, S.J., Berry, S.P., Cooke, E.R.A., Jordan, C.A., Luczo, T.M., \& Jeffriess, M.D. (2014). Relationship between unilateral jumping ability and asymmetry on multidirectional speed in team-sport athletes. Journal of Strength and Conditioning Research, 28(12), 3557-3566.

Los Arcos, A., Yanci, J., Mendiguchia, J., Salinero, J.J., Brughelli, M., \& Castagna, C. (2014). Short-term training effects of vertically and horizontally oriented exercises on neuromuscular performance in professional soccer players. International Journal of Sports Physiology and Performance, 9(3), 480-488.

Magal, M., Smith, R.T., Dyer, J.J., \& Hofman, J.R. (2009). Seasonal variation in physical performance-related variables in male NCAA Division III soccer players. Journal of Strength and Conditioning Research, 23(9), 2555-2559.

Marković, G. (2007). Poor relationship between strength and power qualities and agility performance. Journal of Sports Medicine and Physical Fitness, 47(3), 276-283.

Marković, G., Sekulić, D., \& Marković, M. (2007). Is agility related to strength qualities? - Analysis in latent space. Collegium Antropologicum, 31(3), 787-793.

McCurdy, K.W., Walker, J.L., Langford, G.A., Kutz, M.R., Guerrero, J.M., \& McMillan, J. (2010). The relationship between kinematic determinants of jump and sprint performance in Division I women soccer players. Journal of Strength and Conditioning Research, 24(12), 3200-3208.

Nunnally, J.C., \& Bernstein, I.H. (1994). Psychometric theory. New York: McGraw Hill.

Reilly, T., Williams, A.M., Nevill, A., \& Franks, A. (2000). A multidisciplinary approach to talent identification in soccer. Journal of Sports Sciences, 18(9), 695-702.

Rodriguez-Rosell, D., Mora-Custodio, R., Franco-Márquez, F., Yáñez-García, J.M., \& González-Badillo, J.J. (2017). Traditional vs. sport-specific vertical jump tests: Reliability, validity and relationship with the legs strength and sprint performance in adult and teen soccer and basketball players. Journal of Strength and Conditioning Research, 31(1), 196-206. 
Rosch, D., Hodgson, R., Peterson, T.L., Graf-Baumann, T., Junge, A., Chomiak, I., \& Dvorak, J. (2000). Assessment and evaluation of football performance. The American Journal of Sports Medicine, 28(5 Suppl), S29-S39.

Salaj, S., \& Markovic, G. (2011). Specificity of jumping, sprinting, and quick change-of-direction motor abilities. Journal of Strength and Conditioning Research, 25(5), 1249-1255.

Sarmento, H., Marcelino, R., Anguera, M.T., CampaniÇo, J., Matos, N., \& LeitÃo, J.C. (2014). Match analysis in football: A systematic review. Journal of Sports Sciences, 32(20), 1831-1843.

Sassi, R.H., Dardouri, W., Yahmed, M.H., Gmada, N., Mahfoudhi, M.E., \& Gharbi, Z. (2009). Relative and absolute reliability of a modified agility T-test and its relationship with vertical jump and straight sprint. Journal of Strength and Conditioning Research, 23(6), 1644-1651.

Sheppard, J.M., \& Young, W.B. (2006). Agility literature review: Classifications, training and testing. Journal of Sports Sciences, 24(9), 919-932.

Sheppard, J.M., Young, W.B., Doyle, T.L.A., Sheppard, T.A., \& Newton, R.U. (2006). An evaluation of a new test of reactive agility and its relationship to sprint speed and change of direction speed. Journal of Science and Medicine in Sport, 9(4), 342-349.

Stølen, T., Chamari, K., Castagna, C., \& Wisløff, U. (2005). Physiology of soccer: An update. Sports Medicine, 35(6), 501-536.

Taskin, H. (2008). Evaluating sprinting ability, density of acceleration, and speed dribbling ability of professional soccer players with respect to their positions. Journal of Strength and Conditioning Research, 22(5), 1481-1486.

Vescovi, J.D., \& McGuigan, M.R. (2008). Relationships between sprinting, agility, and jump ability in female athletes. Journal of Sports Science, 25(1), 97-107.

Vigne, G., Gaudino, C., Rogowski, I., Alloatti, G., \& Hautier, C. (2010). Activity profile in elite Italian soccer team. International Journal of Sports Medicine, 31(5), 304-310.

Wisløff, U., Castagna, C., Helgerud, J., Jones, R., \& Hoff, J. (2004). Strong correlation of maximal squat strength with sprint performance and vertical jump height in elite soccer players. British Journal of Sports Medicine, 38(3), 285-288.

Yanci, J., Los Arcos, A., Mendiguchia, J., \& Brughelli, M. (2014). Relationships between sprinting, agility, one- and two-leg vertical and horizontal jump in soccer players. Kinesiology, 46(2), 194-201.

Submitted: December 16, 2015

Accepted: August 18, 2016

Correspondence to:

Asier Los Arcos Larumbe, Ph.D

University of the Basque Country

Faculty of Education and Sport

Lasarte 71, 01007 Vitoria-Gasteiz, Spain

Phone: 0034945013529

E-mail: asier.losarcos@gmail.com 